\title{
sciendo
}

\section{SACCHAROMYCES CEREVISIAE ENHANCED THE GROWTH, IMMUNE AND ANTIOXIDATIVE RESPONSES OF EUROPEAN SEABASS (DICENTRARCHUS LABRAX)}

\author{
Mahmoud A.O. Dawood ${ }^{1}$, Marwa F. Abd El-Kader ${ }^{2}$, Mona A. Farid ${ }^{3}$, Mohamed F. Abd-Elghany ${ }^{4}$, \\ Mohamed Alkafafy ${ }^{5}$, Hien Van Doan ${ }^{6,7}$
}

\author{
${ }^{1}$ Department of Animal Production, Faculty of Agriculture, Kafrelsheikh University, 33516, \\ Kafrelsheikh, Egypt \\ ${ }^{2}$ Department of Fish Diseases and Management, Sakha Aquaculture Research Unit, Central Laboratory \\ for Aquaculture Research, A.R.C., Egypt \\ ${ }^{3}$ Genetics Department, Faculty of Agriculture, Kafrelsheikh University, Kafr El-Sheikh, 33516, Egypt \\ ${ }^{4}$ Department of Animal Production, Faculty of Agriculture, Al-Azhar University, Cairo 11884, Egypt \\ ${ }^{5}$ Department of Biotechnology, College of Science, Taif University, P.O. Box 11099, Taif 21944, \\ Saudi Arabia \\ ${ }^{6}$ Department of Animal and Aquatic Sciences, Faculty of Agriculture, Chiang Mai University, Chiang \\ Mai 50200, Thailand \\ ${ }^{7}$ Science and Technology Research Institute, Chiang Mai University, 239 Huay Keaw Rd., Suthep, \\ Muang, Chiang Mai 50200, Thailand \\ •Corresponding author: hien.d@cmu.ac.th
}

\begin{abstract}
The concept of probiotics is widely applied in the field of aquaculture for their beneficial and friendly influences. In this sense, the role of Saccharomyces cerevisiae on the growth, immune and antioxidative responses of European seabass was tested in this study. Fish were distributed in 3 groups (triplicates) with ten fish in each replicate and fed 0,1 , and $2 \mathrm{~g} / \mathrm{kg}$ of $S$. cerevisiae $\left(15 \times 10^{9} \mathrm{CFU} / \mathrm{g}\right)$ for 90 days. Fish fed $S$. cerevisiae showed higher final body, weight gain, and specific growth rate as well as lower FCR than fish fed the basal diet $(\mathrm{P}<0.05)$. The $\mathrm{RBCs}$, WBCs, $\mathrm{Hb}$, and PCV values were increased in fish fed dietary $S$. cerevisiae when compared to the control $(\mathrm{P}<0.05)$. The blood total protein, albumin, and globulin were higher in fish fed $S$. cerevisiae than the control $(\mathrm{P}<\mathbf{0 . 0 5})$. Fish fed dietary $S$. cerevisiae had enhanced phagocytic index, phagocytic, and lysozyme activity comparing the control. In a similar sense, the antioxidative enzymes (SOD, GPx, and CAT) were higher in fish fed $S$. cerevisiae than the control $(\mathrm{P}<0.05)$. However, the level of MDA was lowered $(\mathrm{P}<0.05)$ by $S$. cerevisiae in European seabass. Gene expression of $I L-8, I L-1 \beta$, $G H$, and $I G F-1$ was upregulated and $H S P 70$ was downregulated by $S$. cerevisiae $(\mathrm{P}<0.05)$. It can be concluded that European seabass fed $S$. cerevisiae at 1-2 $\mathrm{g} / \mathrm{kg}\left(15 \times 10^{9} \mathrm{CFU} / \mathrm{g}\right)$ diet had markedly enhanced growth, haemato-biochemical, and immune performances.
\end{abstract}

Key words: European seabass, probiotics, growth performance, immunity, stress resistance 
Fisheries and aquaculture contribute significantly to human food security (FAO, 2018). Due to the large increase in consumption and the increasing demand for seafood, fish can be farmed with high densities. As a result, fish were subjected to stress in ponds which are associated with immunosuppression (Abdel-Latif et al., 2020; Dawood and Koshio, 2020). Thus, the fish's susceptibility to infectious diseases increases, which causes huge economic losses. In such cases, the use of antibiotics is the traditional treatment for fish, but frequent use of antibiotics has caused many of the harms related to fish, the consumer, and the environment (Garlock et al., 2020). Many countries have limited the use of antibiotics and replaced it with a wide range of effective natural alternatives (Cao et al., 2020; Yilmaz et al., 2018). Indeed, effective alternatives have been tested, which include probiotics, prebiotics, immunostimulants, and medicinal plants (Ahmadifar et al., 2020; Dawood et al., 2018).

Probiotics are live microorganisms involved in regulating the diversity of beneficial microbiota in aquatic organisms' intestinal tract (Kuebutornye et al., 2019). More specifically, beneficial bacteria and yeasts (e.g., Lactobacillus, Bacillus, and Saccharomyces) are the famous probiotic species that have been widely applied (Iwashita et al., 2015; Y1lmaz et al., 2020). Markedly, fish treated with dietary probiotics displayed enhanced local intestinal digestion and immunity with association with entire body immunity (Dawood et al., 2020 b). Additionally, probiotics effectively enrich the intestinal environment with functional metabolites and antimicrobial agents that compete with pathogenic biota (Dawood et al., 2019; Yao et al., 2020). Therefore, probiotics' inclusion results in enhanced resistance against oxidative and disease challenges (Abu-Elala et al., 2013; Reque et al., 2010). Yeast is an effective probiotic involved in several beneficial effects when supplied to aquatic organisms (Huyben et al., 2017). The oral delivery of Saccharomyces cerevisiae beneficially impacted the growth, feed efficiency, immunity, and resistance to infectious diseases in Nile tilapia (Oreochromis niloticus) (Abass et al., 2018; Dawood et al., 2020 c), African catfish (Clarias gariepinus) (Essa et al., 2011), common carp (Cyprinus carpio) (Huang et al., 2015), Atlantic salmon (Salmo salar) (Hansen et al., 2021), and grouper (Epinephelus coioides) (Yang et al., 2020).

European seabass (Dicentrarchus labrax) is marketable farmed fish and known for its high-food quality properties (Magalhães et al., 2017). Dietary probiotics are a vital factor for improving fish productivity and profitability, but probiotics for improving seabass performances are still not well documented. Thus, this study spotlights on evaluating the oral delivery effect of $S$. cerevisiae on the growth, immune, and antioxidative responses of European seabass.

\section{Material and methods}

\section{Design and procedures}

Commercial diet (45\% crude protein, AQUA International for Food Industries, Cairo, Egypt) was considered as a basal diet and well mixed with varying levels $(0,1$, and $2 \mathrm{~g} / \mathrm{kg})$ of $S$. cerevisiae $\left(15 \times 10^{9} \mathrm{CFU} / \mathrm{g}\right.$, AGRANCO CORP., USA $)$ in the presence of fish oil every two weeks and kept at $4^{\circ} \mathrm{C}$ until use. 
Fingerlings of European seabass with visually average initial size and an average weight of $20.53 \pm 0.10 \mathrm{~g}$ were stocked in nine hapas $(1 \times 2 \times 1.25 \mathrm{~m}$ each $)$ with the rate of 10 fish per hapa. Before initiating the trial, fish were fed the basal diet and kept for ten days for adaptation under optimal farming conditions. Fish were fed the prepared diets on 09:00, 12:00, and 15:00 h till satiation level for 90 days. Water characteristics were kept optimally during the trial; 18.0 to $19.0^{\circ} \mathrm{C}, 4.8$ to $5.32 \mathrm{mg} / \mathrm{L}$, 7.0 to 7.5 , from 0.03 to $0.038 \mathrm{mg} / \mathrm{L}, 23.41 \mathrm{ppt}$, for temperature, dissolved oxygen, $\mathrm{pH}$, ammonia $\left(\mathrm{NH}_{3}\right)$, and total salinity, respectively.

\section{Final sampling}

All fish were weighed for final growth performance calculation using the following formulae:

$$
\begin{gathered}
W G=W 2(g)-W 1(g) ; F C R=F I(g) / W G(g) ; S G R=100 \times((\ln W 2(g)-\ln W 1 \\
(g)) / \text { time }(\text { day }))
\end{gathered}
$$

where: $W 2$ : final weight; $W 1$ : initial weight; $W G$ : weight gain $(\mathrm{g}) ; F C R$ : feed conversion ratio; $S G R$ : specific growth rate.

Fish were anesthetized (MS-222: $25 \mathrm{mg} / \mathrm{L}$ ) then blood was obtained from five fish per hapa. One-half of the blood was kept in heparinized tubes $(1600 \mathrm{UI} / \mathrm{ml})$ to assess hematological traits. Another tube without coagulant agent serum was collected for serum samples, centrifuged at $3000 \mathrm{rpm} / 15 \mathrm{~min}$ at $4^{\circ} \mathrm{C}$, and stored at $-20^{\circ} \mathrm{C}$.

\section{Blood analysis}

The red blood cell counts (RBCs) were determined by following Blaxhall and Daisley (1973) and Hrubec and Smith (1999). Hematocrit (PCV) was determined by using microhematocrit. Hemoglobin concentrations $(\mathrm{Hb})$ were determined by the cyanhemoglobin method, at $540 \mathrm{~nm}$. The count of white blood cells was analyzed by following Stoskopf (1993).

The total serum protein (sTP; g/dL) and albumin (ALB; g/dL) were determined by following Doumas et al. (1981) and Reinhold (1953), respectively. Globulin (GLB; g/dL) was calculated by subtracting ALB from sTP. Serum aspartate aminotransferase (AST) and alanine aminotransferase (ALT) activities were examined by following Gella et al. (1985).

The turbidimetric assay followed to analyze lysozyme activity according to Ellis et al. (1990). The phagocytosis assay was analyzed by following Cai et al. (2004) and Kawahara et al. (1991). Glutathione peroxidase (GPx), superoxide dismutase (SOD), catalase (CAT), and malonaldehyde (MDA) levels were detected using diagnostic reagent kits (Cusabio Biotech Co., Ltd.; China).

\section{Gene expression}

The expression of hepatic genes was determined using RT-PCR. Briefly, TRIzol reagent (Invitrogen, Life Technologies, Carlsbad, CA, USA) was utilized to extract 
total RNA from approximately $100 \mathrm{mg}$ of hepatic tissue. RNA samples of 1.8 or more A260 / A280 were used for DNA synthesis using a cDNA synthesis package (Fermentas, Waltham, MA, United States) using Nanodrop quantitative. The SYBR Green Master Mix with GAPDH as a standard gene have been added to amplify cDNA. The primers were designed by following Abd El-Kader et al. (2020). Obtained results on amplification were assessed using $2^{-\Delta \Delta}$ methods (Pfaffl, 2001).

\section{Statistical analyses}

All data were statistically analysed using one-way ANOVA with SPSS (version 22, SPSS Inc., IL, USA). Duncan's test was used to determine the significant differences at the level of $5 \%$.

\section{Results}

\section{Growth performance}

Fish fed $S$. cerevisiae revealed higher $(\mathrm{P}<0.05)$ final body, weight gain, and specific growth rate but lower feed conversion ratio than fish fed $S$. cerevisiae free diet (Table 1).

Table 1. The effect of $S$. cerevisiae on the growth performance of European seabass

\begin{tabular}{l|c|c|c}
\hline \multicolumn{1}{c}{ Item } & 0 & 1 & \multicolumn{1}{c}{2} \\
\hline IBW (g) & $24.08 \pm 0.02$ & $23.84 \pm 0.04$ & $24.30 \pm 0.05$ \\
FBW (g) & $99.52 \pm 0.22 \mathrm{a}$ & $119.98 \pm 0.23 \mathrm{~b}$ & $122.59 \pm 0.31 \mathrm{~b}$ \\
WG (\%) & $75.43 \pm 0.20 \mathrm{a}$ & $96.14 \pm 0.19 \mathrm{~b}$ & $98.29 \pm 0.32 \mathrm{~b}$ \\
SGR (\%/day) & $1.69 \pm 0.00 \mathrm{a}$ & $1.92 \pm 0.00 \mathrm{~b}$ & $1.93 \pm 0.00 \mathrm{~b}$ \\
FCR & $1.47 \pm 0.04 \mathrm{~b}$ & $1.12 \pm 0.01 \mathrm{a}$ & $1.07 \pm 0.03 \mathrm{a}$ \\
\hline
\end{tabular}

Each row presents mean \pm S.E. and different letters refer to significant differences $(\mathrm{P}<0.05)$.

\section{Blood traits}

The blood profile of fish fed $S$. cerevisiae showed normal average values (Table 2). Markedly, RBCs, WBCs, Hb, and PCV have increased in fish treated with $S$. cerevisiae than in control $(\mathrm{P}<0.05)$.

Table 3 presents the biochemical blood indices, including ALT, AST, sTP, ALB, and GLB. The sTP, ALB, and GLB were higher in fish fed $S$. cerevisiae than the control $(\mathrm{P}<0.05)$.

Fish fed dietary S. cerevisiae had enhanced phagocytic index, phagocytic, and lysozyme activity compared to control (Table 4). In a similar sense, the antioxidative enzymes (SOD, GPx, and CAT) were higher in fish fed $S$. cerevisiae than the control $(\mathrm{P}<0.05)$ (Table 5). However, the level of MDA was considerably lowered by $S$. cerevisiae in European seabass $(\mathrm{P}<0.05)$ (Table 5). 
Table 2. The effect of S. cerevisiae on the hematological indices of European seabass

\begin{tabular}{lccc}
\hline \multicolumn{1}{c}{ Item } & 0 & 1 & 2 \\
\hline $\mathrm{Hb}(\mathrm{g} / 100 \mathrm{ml})$ & $9.99 \pm 0.01 \mathrm{a}$ & $11.64 \pm 0.08 \mathrm{~b}$ & $11.70 \pm 0.01 \mathrm{~b}$ \\
$\mathrm{RBCs}\left(10 / \mathrm{mm}^{6}\right)$ & $3.19 \pm 0.01 \mathrm{a}$ & $3.71 \pm 0.01 \mathrm{vb}$ & $3.76 \pm 0.01 \mathrm{~b}$ \\
$\mathrm{PCV}(\%)$ & $31.50 \pm 0.29 \mathrm{a}$ & $36.50 \pm 0.29 \mathrm{~b}$ & $37.00 \pm 0.00 \mathrm{~b}$ \\
$\mathrm{MCV}\left(\mathrm{mm}^{3}\right)$ & $98.74 \pm 0.55$ & $98.38 \pm 0.47$ & $98.40 \pm 0.15$ \\
$\mathrm{MCH}(\mathrm{Pg})$ & $31.32 \pm 0.10$ & $31.37 \pm 0.12$ & $31.12 \pm 0.06$ \\
$\mathrm{MCHC}(\%)$ & $31.72 \pm 0.27$ & $31.89 \pm 0.03$ & $31.62 \pm 0.02$ \\
WBCs (10/mm $)$ & $18.63 \pm 0.27 \mathrm{a}$ & $20.51 \pm 0.01 \mathrm{~b}$ & $20.58 \pm 0.01 \mathrm{~b}$ \\
Heterophils (\%) & $12.00 \pm 0.00$ & $10.50 \pm 0.29$ & $12.50 \pm 0.29$ \\
Lymphocytes (\%) & $77.00 \pm 0.00$ & $81.50 \pm 0.29$ & $78.00 \pm 0.00$ \\
Monocytes (\%) & $7.50 \pm 0.29$ & $7.00 \pm 0.00$ & $8.00 \pm 0.00$ \\
Eosinophils (\%) & $1.50 \pm 0.29$ & $0.50 \pm 0.29$ & $0.50 \pm 0.29$ \\
Basophils (\%) & $2.00 \pm 0.00$ & $0.50 \pm 0.29$ & $1.00 \pm 0.00$ \\
\hline
\end{tabular}

Each row presents mean \pm S.E. and different letters refer to significant differences $(\mathrm{P}<0.05)$.

Table 3. The effect of $S$. cerevisiae on the biochemical parameters of European seabass

\begin{tabular}{l|c|c|c}
\hline \multicolumn{1}{c|}{ Item } & 0 & 1 & 2 \\
\hline ALT (U/I) & $29.96 \pm 0.06$ & $29.58 \pm 0.52$ & $29.37 \pm 0.22$ \\
AST (U/I) & $32.64 \pm 0.28$ & $30.94 \pm 0.05$ & $30.27 \pm 0.01$ \\
Blood total protein (mg/dl) & $4.62 \pm 0.00 \mathrm{a}$ & $4.84 \pm 0.01 \mathrm{~b}$ & $4.87 \pm 0.01 \mathrm{~b}$ \\
Albumin (g/dl) & $1.46 \pm 0.00 \mathrm{a}$ & $1.55 \pm 0.01 \mathrm{~b}$ & $1.63 \pm 0.00 \mathrm{~b}$ \\
Globulin (g/dl) & $3.16 \pm 0.00 \mathrm{a}$ & $3.29 \pm 0.01 \mathrm{~b}$ & $3.23 \pm 0.01 \mathrm{~b}$
\end{tabular}

Each row presents mean \pm S.E. and different letters refer to significant differences $(P<0.05)$.

Table 4. The effect of $S$. cerevisiae on the immune parameters of European seabass

\begin{tabular}{l|c|r|r}
\hline \multicolumn{1}{c|}{ Item } & 0 & 1 & \multicolumn{1}{c}{2} \\
\hline Lysozyme activity (unit/ml) & $11.68 \pm 0.02 \mathrm{a}$ & $12.76 \pm 0.02 \mathrm{~b}$ & $12.89 \pm 0.00 \mathrm{~b}$ \\
Phagocytic activity (\%) & $17.09 \pm 0.02 \mathrm{a}$ & $20.67 \pm 0.01 \mathrm{~b}$ & $20.82 \pm 0.01 \mathrm{~b}$ \\
Phagocytic index & $1.02 \pm 0.00 \mathrm{a}$ & $1.23 \pm 0.01 \mathrm{~b}$ & $1.27 \pm 0.04 \mathrm{~b}$ \\
\hline
\end{tabular}

Each row presents mean \pm S.E. and different letters refer to significant differences $(\mathrm{P}<0.05)$.

Table 5. The effect of antioxidative status of European seabass

\begin{tabular}{l|c|c|c}
\hline \multicolumn{1}{c|}{ Item } & 0 & 1 & 2 \\
\hline SOD (IU/I) & $9.94 \pm 0.05 \mathrm{a}$ & $10.48 \pm 0.02 \mathrm{~b}$ & $11.30 \pm 0.01 \mathrm{~b}$ \\
CAT (IU/I) & $12.08 \pm 0.02 \mathrm{a}$ & $12.48 \pm 0.01 \mathrm{~b}$ & $12.53 \pm 0.02 \mathrm{~b}$ \\
GPx (IU/I) & $13.60 \pm 0.02 \mathrm{a}$ & $13.99 \pm 0.00 \mathrm{ab}$ & $14.03 \pm 0.01 \mathrm{~b}$ \\
MDA (IU/I) & $20.01 \pm 0.08 \mathrm{~b}$ & $18.65 \pm 0.01 \mathrm{a}$ & $18.40 \pm 0.09 \mathrm{a}$ \\
\hline
\end{tabular}

Each row presents mean \pm S.E. and different letters refer to significant differences $(\mathrm{P}<0.05)$. 


\section{Levels of mRNA transcription}

The mRNA levels of $G H, I G F-1, I L-8$, and $I L-1 \beta$ genes were markedly increased by $S$. cerevisiae; however, the level of $H S P 70$ gene was decreased $(\mathrm{P}<0.05)$ (Figure 1).
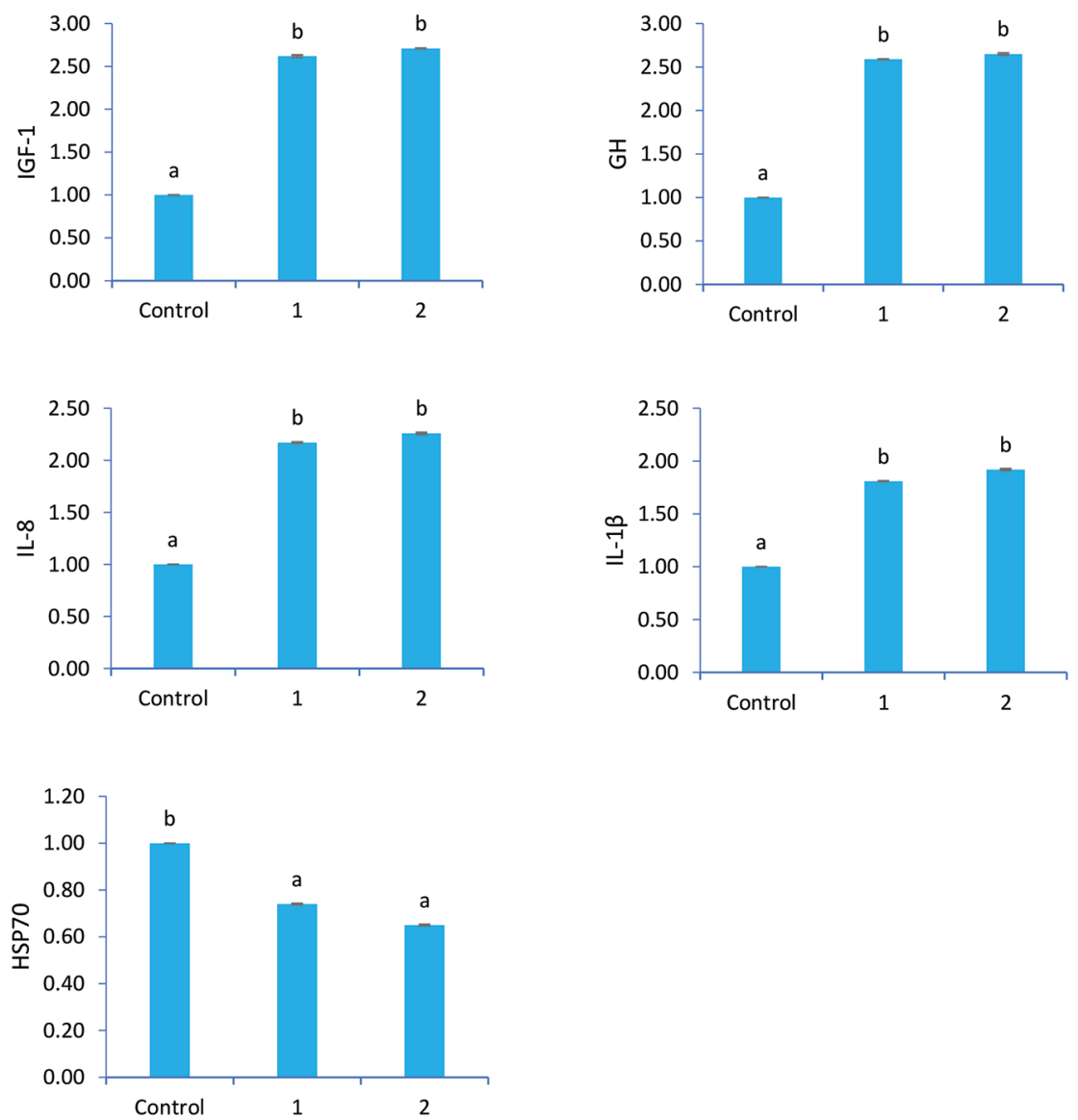

Figure 1. The influence of S. cerevisiae on $G H, I G F-1, H S P 70, I L-8$, and $I L-1 \beta$ gene expression. Bars present mean \pm S.E. $(n=3)$. Different superscript letters refer to marked changes between groups $(\mathrm{P}<0.05)$

\section{Discussion}

The potential impact of probiotics as alternative antibiotic substances has been clearly investigated in aquaculture, focusing on dietary $S$. cerevisiae that is involved in enhancing the growth performance and health condition (Dawood, 2021). Firstly, the oral delivery of $S$. cerevisiae competes with pathogenic microorganisms in the 
intestinal tract and acts as an antibacterial potent. Further, it increases the diversity of intestinal microbiota and allows the beneficial biota to beneficially enhance the digestion and absorption of nutrients in the local intestine. Concurrently, the local immunity would be enhanced, and the entire body immunity can be activated.

This study showed enhanced growth performance in European seabass given 1-2 g/kg of S. cerevisiae. The results agree with Abass et al. (2018), Essa et al. (2011), Huang et al. (2015), Hansen et al. (2021), and Yang et al. (2020), who reported an enhanced growth rate of Nile tilapia, African catfish, common carp, Atlantic salmon, and grouper fed dietary $S$. cerevisiae. S. cerevisiae has abundant intracellular proteins in their cell walls that improve feed utilization through the intestinal tract. Besides. $S$. cerevisiae increases the abundance of beneficial microbiota in the intestinal tract of fish, which sector digestive enzymes for the digestion of feeds (Hindu et al., 2019). The enhanced absorption of digested nutrients is also attributed to the role of $S$. cerevisiae that assists in absorbing nutrients through the epithelium tissue to the bloodstream then for the entire cells. The enhancement of feed utilization led to increased feed consumption and improving FCR value, which refers to improved feed digestibility and weight gain (Dawood, 2021). Interestingly, the results also displayed upregulated $G H$ and $I G F-1$ genes in seabass treated with $S$. cerevisiae. These results refer to the potential role of $S$. cerevisiae in enhancing the growth-related factor on a molecular basis, which led to enhanced weight gain in this study. Similarly, dietary probiotics resulted in increasing the mRNA levels of growth-related genes in aquatic organisms (Dawood et al., 2020 a).

Usually, when fish could utilize feed properly, it can be assumed that the metabolic function, immune system, and health condition of fish could be enhanced. The study displayed increased RBCs, WBCs, PCV, and $\mathrm{Hb}$ values in seabass treated with 1-2 g S. cerevisiae $/ \mathrm{kg}$. As probiotic cells, S. cerevisiae is known for its role in regulating metabolic function in association with enhancing the immune system of fish (Takahashi et al., 2017). In this sense, increased RBCs and Hb levels referring to a sufficient amount of nutrients in the blood without anemic features with a potential role in respiration and oxygen exchange. Additionally, increased WBCs and PCV indicate enhanced immunity and defense against pathogenic invaders (Fiúza et al., 2015). Similarly, Nile tilapia receiving $S$. cerevisiae showed improved WBCs, Hb, RBCs, and PCV indices (Dawood et al., $2020 \mathrm{c}$ ).

The blood total protein (sTP), albumin (ALB), and globulin (GLB) traits are involved in many physiological functions in the fish body (Shi et al., 2006). High levels of sTP indicate the availability of protein in the blood required for metabolic functions with the relevance of the immune status. ALB is another blood protein that defends against the leakage of vessels induced by stressors, while GLB plays a vital role in the humoral immune response (Uribe et al., 2011). This study showed an improved sTP, ALB, and GLB levels in fish fed S. cerevisiae, which illustrates the enhanced metabolic and health responses of seabass. These results are in line with Dawood et al. (2020 c) who reported enhanced sTP and GLB in Nile tilapia treated with probiotics.

Phagocytic activity (PA) is anti-bacterial function involved in the protection against infection (Itou et al., 1996). Another vital tool during the infection is the 
lysozyme activity (LA) that breaks down the cell walls of pathogenic bacteria and acts as a non-specific immune response (Tort et al., 2003). The study showed enhanced PA and LA in fish given $S$. cerevisiae, which agrees with Abu-Elala et al. (2013), who reported enhanced LA in Nile tilapia fed S. cerevisiae.

Stressful farming conditions result in oxidative stress involved in ROS generation that oxidizes the cellular lipid content and breaks down RNA (Martínez-Álvarez et al., 2005). The high levels of lipid peroxidation and expressed by producing malondialdehyde (MDA) (Brewer, 2011), which activates the antioxidant enzymes such as SOD, CAT, and GPx to defend against ROS production (Li et al., 2007). In this study, the activities of SOD, CAT, and GPx were enhanced while MDA level was decreased in fish delivered $S$. cerevisiae. Concurrently, Nile tilapia fed $S$. cerevisiae showed an enhanced antioxidative response (Abu-Elala et al., 2013).

Under stressful conditions, HSP70 protects cells and enhances cellular immunity (Ming et al., 2010). Cytokines like interleukin 12 (IL-12) regulate the function of IL-8 and IL-1 $\beta$ as pro-inflammatory responses during infection through cell proliferation, differentiation, and apoptosis (Ethuin et al., 2001; Liu et al., 2005). The study revealed reduced expression of HSP70 in fish fed dietary S. cerevisiae showing the absence of inflammation and stressful conditions. The immune response was further quantified by the detection of the immune-related genes (IL-1 $\beta$ and IL-8) which displayed upregulated expressions in fish fed $S$. cerevisiae. Yeast wall has abundant amounts of $\beta$-glucans and mannan oligosaccharides which are responsible for the immunomodulation and the resistance against pathogens in aquatic animals (Dawood and Koshio, 2016; Yang et al., 2020). Concurrently, $\beta$-glucans easily recognize the receptors of $\beta$-glucan binding proteins in the immune cells and stimulate the innate immune system (Magnadóttir, 2006).

In parallel, Hansen et al. (2021) illuminated that salmon fed dietary S. cerevisiae had increased IL-1 $\beta$ and IL-8 levels. Furthermore, Abu-Elala et al. (2020) stated that Nile tilapia fed dietary $S$. cerevisiae had upregulated IL-1 $\beta$ and IL-8 gene expressions.

\section{Conclusion}

The obtained results revealed that $S$. cerevisiae could be supplemented in the diets of European seabass at $1-2 \mathrm{~g} / \mathrm{kg}\left(15 \times 10^{9} \mathrm{CFU} / \mathrm{g}\right)$ to improve the growth performance, feed efficiency, blood health, antioxidative status, and immune-related genes.

\section{Acknowledgments}

Taif University Researchers Supporting Project number (TURSP-2020/57), Taif University, P.O. Box 11099, Taif 21944, Saudi Arabia. This research work was partially supported by Chiang Mai University.

\section{Funding}

The current work was funded by Taif University Researchers Supporting Project number (TURSP - 2020/57), Taif University, Taif, Saudi Arabia. This research work was partially supported by Chiang Mai University. 


\section{References}

A b a s s D.A., O b irik or ang K.A., C a m p i o n B.B., Ed zi y i e R.E., S k o v P.V. (2018). Dietary supplementation of yeast (Saccharomyces cerevisiae) improves growth, stress tolerance, and disease resistance in juvenile Nile tilapia (Oreochromis niloticus). Aquacult. Int., 26: 843-855.

Abd El-Kader M.F., E1-B ab A.F.F., Abd-Elghany M.F., Abdel-Warith A.-W.A., Younis E.M., Daw ood M.A. (2020). Selenium nanoparticles act potentially on the growth performance, hemato-biochemical indices, antioxidative, and immune-related genes of European seabass (Dicentrarchus labrax). Biol. Trace Elem. Res., 1-9.

A b d e l- Lat if H.M.R., A b d e l- Taw w a b M., K ha fa ga A.F., D a w o od M.A.O. (2020). Dietary oregano essential oil improved the growth performance via enhancing the intestinal morphometry and hepato-renal functions of common carp (Cyprinus carpio L.) fingerlings. Aquaculture, 526: 735432 .

A b u - E l a l a N., M a r z o u k M., M o u s t a fa M. (2013). Use of different Saccharomyces cerevisiae biotic forms as immune-modulator and growth promoter for Oreochromis niloticus challenged with some fish pathogens. Int. J. Vet. Sci. Med., 1: 21-29.

Abu-Elala N.M., Youn is N.A., AbuBakr H.O., Raga a N.M., B orges L.L., B ona to M.A. (2020). Influence of dietary fermented Saccharomyces cerevisiae on growth performance, oxidative stress parameters, and immune response of cultured Oreochromis niloticus. Fish Physiol. Biochem., 46: 533-545.

Ahmadifar E., Yous efi M., Karimi M., Fadaei Raieni R., Dadar M., Yilmaz S., D a w o od M.A., A b d e l - L a t if H.M. (2020). Benefits of dietary polyphenols and polyphenolrich additives to aquatic animal health: an overview. Rev. Fish. Sci. Aquac., 1-34.

B la xhall P.C., Da is ley K.W. (1973). Routine haematological methods for use with fish blood. J. Fish Biol., 5: 771-781.

B r e w e r M.S. (2011). Natural antioxidants: sources, compounds, mechanisms of action, and potential applications. Compr. Rev. Food Sci. F., 10: 221-247.

C a i W.-Q., L i S.-F., M a J.-Y. (2004). Diseases resistance of Nile tilapia (Oreochromis niloticus), blue tilapia (Oreochromis aureus) and their hybrid (female Nile tilapia $\times$ male blue tilapia) to Aeromonas sobria. Aquaculture, 229: 79-87.

C a o Y., L i u H., Q in N., R e n X., Z h u B., X i a X. (2020). Impact of food additives on the composition and function of gut microbiota: A review. Trends Food Sci. Technol., 99: 295-310.

D a w o o d M.A.O. (2021). Nutritional immunity of fish intestines: important insights for sustainable aquaculture. Rev. Aquacult., 13: 642-663.

D a w o o d M.A.O., K o shio S. (2016). Recent advances in the role of probiotics and prebiotics in carp aquaculture: A review. Aquaculture, 454: 243-251.

D a w o o d M.A.O., K o s h i o S. (2020). Application of fermentation strategy in aquafeed for sustainable aquaculture. Rev. Aquacult., 12: 987-1002.

D a w o o d M.A.O., K o s hi o S., Es t e b a n M.Á. (2018). Beneficial roles of feed additives as immunostimulants in aquaculture: a review. Rev. Aquacult., 10: 950-974.

D a w o o d M.A.O., K o s h i o S., A b d el - D a i m M.M., Va n D o an H. (2019). Probiotic application for sustainable aquaculture. Rev. Aquacult., 11: 907-924.

D a w o o d M.A., A b o - A 1 - E l a H.G., H a s a n M.T. (2020 a). Modulation of transcriptomic profile in aquatic animals: Probiotics, prebiotics and synbiotics scenarios. Fish Shellfish Immunol., 97: $268-282$.

D a w o o d M.A., E w e e d a h N.M., M o u s t a fa E.M., F a r a h a t E.M. (2020 b). Probiotic effects of Aspergillus oryzae on the oxidative status, heat shock protein, and immune related gene expression of Nile tilapia (Oreochromis niloticus) under hypoxia challenge. Aquaculture, 520: 734669.

D a w o o d M.A.O., E w e e d a h N.M., Kh a 1 a fa 11 a M.M., Khalid A., A s e 1 y A.E., F a d 1 S.E., A m in A.A., Paray B.A., Ahmed H.A. (2020 c). Saccharomyces cerevisiae increases the acceptability of Nile tilapia (Oreochromis niloticus) to date palm seed meal. Aquacult. Rep., 17: 100314.

D ou mas B.T., B ay se D.D., Carter R.J., P eters T., S chaffer R. (1981). A candidate reference method for determination of total protein in serum. I. Development and validation. Clin. Chem., 27: 1642-1650. 
Ellis A., Stolen J., Fletcher T., Anderson D., Robertson B., Van Muiswinkel W. (1990). Lysozyme assay. Tech. Fish Immunol., 1: 101-103.

E s s a M.A., M a b r o u k H.A., M o ha m e d R.A., M i c h a e 1 F.R. (2011). Evaluating different additive levels of yeast, Saccharomyces cerevisiae, on the growth and production performances of a hybrid of two populations of Egyptian African catfish, Clarias gariepinus. Aquaculture, 320: 137-141.

Ethuin F., D e la r che C., B ens la ma S., Gougerot - P o c id a lo M.-A., J a c ob L., Chol let-M a r in S. (2001). Interleukin-12 increases interleukin 8 production and release by human polymorphonuclear neutrophils. J. Leukoc. Biol., 70: 439-446.

FAO (2018). Aquaculture Department. The state of world fisheries and aquaculture. Rome.

Fiúza L.S., Aragão N.M., Ribeiro Junior H.P., de Moraes M.G., Rocha Í.R.C.B., Lustosa Neto A.D., de Sousa R.R., Madrid R.M.M., de Oliveira E.G., Cos t a F.H.F. (2015). Effects of salinity on the growth, survival, haematological parameters and osmoregulation of tambaqui Colossoma macropomum juveniles. Aquacult. Res., 46: 1-9.

Garlock T., Asche F., Anderson J., Bjørndal T., Kumar G., Lorenzen K., Ropick i A., S m i th M.D., T v e t e rå s R. (2020). A global blue revolution: Aquaculture growth across regions, species, and countries. Rev. Fish. Sci. Aquac., 28: 107-116.

Gella F.J., Olivella T., Pastor M.C., Arenas J., Moreno R., Durban R., Go mez J.A. (1985). A simple procedure for the routine determination of aspartate aminotransferase and alanine aminotransferase with pyridoxal phosphate. Clin. Chim. Acta., 153: 241-247.

Hansen J.Ø., Lagos L., Lei P., Reveco-Urzua F.E., Morales-Lange B., Hansen L.D., Schiavone M., Mydland L.T., Arntzen M.Ø., Mercado L., Benicio R.T., Ø v e r l a n d M. (2021). Down-stream processing of baker's yeast (Saccharomyces cerevisiae) - Effect on nutrient digestibility and immune response in Atlantic salmon (Salmo salar). Aquaculture, 530: 735707.

Hindu S.V., Chandras ekaran N., Mukherjee A., Thom as J. (2019). A review on the impact of seaweed polysaccharide on the growth of probiotic bacteria and its application in aquaculture. Aquacult. Int., 27: 227-238.

H r u b e c T.C., S m it h S.A. (1999). Differences between plasma and serum samples for the evaluation of blood chemistry values in rainbow trout, channel catfish, hybrid tilapias, and hybrid striped bass. J. Aquat. Anim. Health., 11: 116-122.

Huang L., R an C., He S., R en P., H u J., Z h a o X., Z h o u Z. (2015). Effects of dietary Saccharomyces cerevisiae culture or live cells with Bacillus amyloliquefaciens spores on growth performance, gut mucosal morphology, hsp70 gene expression, and disease resistance of juvenile common carp (Cyprinus carpio). Aquaculture, 438: 33-38.

Huyben D., Nyman A., Vidaković A., Passoth V., Moccia R., Kiessling A., Dicksved J., Lundh T. (2017). Effects of dietary inclusion of the yeasts Saccharomyces cerevisiae and Wickerhamomyces anomalus on gut microbiota of rainbow trout. Aquaculture, 473: $528-537$.

I t o u T., L i d a T., K a w a t s u t H. (1996). Kinetics of oxygen metabolism during respiratory burst in Japanese eel neutrophils. Dev. Comp. Immunol., 20: 323-330.

I w a s h it a M.K.P., Nakandakare I.B., Terhune J.S., Wood T., Ranzani-Paiva M.J.T. (2015). Dietary supplementation with Bacillus subtilis, Saccharomyces cerevisiae and Aspergillus oryzae enhance immunity and disease resistance against Aeromonas hydrophila and Streptococcus iniae infection in juvenile tilapia Oreochromis niloticus. Fish Shellfish Immunol., 43: 60-66.

K aw ahara E., U ed a T., N o mura S. (1991). In vitro phagocytic activity of white-spotted char blood cells after injection with Aeromonas salmonicida extracellular products. Fish Path., 26: $213-214$.

Kuebutornye F.K.A., A barike E.D., L u Y. (2019). A review on the application of Bacillus as probiotics in aquaculture. Fish Shellfish Immunol., 87: 820-828.

L i X.M., Ma Y.L., Li u X.J. (2007). Effect of the Lycium barbarum polysaccharides on age-related oxidative stress in aged mice. J. Ethnopharmacol., 111: 504-511.

Li u J., Ca o S., Ki m S., Chung E.Y., H o m m a Y., Gu a n X., J i m e ne z V., M a X. (2005). Interleukin-12: an update on its immunological activities, signaling and regulation of gene expression. Curr. Immunol. Rev., 1: 119-137.

Magalhães R., Sánchez-López A., Leal R.S., Martínez-Llorens S., Oliva-Te- 
le s A., P e res H. (2017). Black soldier fly (Hermetia illucens) pre-pupae meal as a fish meal replacement in diets for European seabass (Dicentrarchus labrax). Aquaculture, 476: 79-85.

$\mathrm{M}$ a g $\mathrm{n}$ a dó $\mathrm{t} t$ i r B. (2006). Innate immunity of fish (overview). Fish Shellfish Immunol., 20: 137-151.

Martín e z - Álvare z R.M., M or a les A.E., S a n z A. (2005). Antioxidant defenses in fish: Biotic and abiotic factors. Rev. Fish Biol. Fish., 15: 75-88.

Ming J., Xi e J., Xu P., Li u W., Ge X., Li u B., He Y., Cheng Y., Zhou Q., P an L. (2010). Molecular cloning and expression of two HSP70 genes in the Wuchang bream (Megalobrama amblycephala Yih). Fish Shellfish Immunol., 28: 407-418.

Pfaffl M.W. (2001). A new mathematical model for relative quantification in real-time RT-PCR Nucleic Acids Res., 29: e45.

R e in h o ld J. (1953). Total protein, albumin and globulin. Standard Methods of Clinical Chemistry. 1.

Reque V.R., de Moraes J.R.E., de Andrade Belo M.A., d e Moraes F.R. (2010). Inflammation induced by inactivated Aeromonas hydrophila in Nile tilapia fed diets supplemented with Saccharomyces cerevisiae. Aquaculture, 300: 37-42.

Shi X., Li D., Zhuang P., N i e F., L ong L. (2006). Comparative blood biochemistry of Amur sturgeon, Acipenser schrenckii, and Chinese surgeon, Acipenser sinensis. Fish Physiol. Biochem., 32: 63 .

S t o s k o p f M. (1993). Fish Medicine. WB Saunders Comp. Philadelphia.

Takahashi L.S., Biller-Takahashi J.D., Mansano C.F.M., Urbinati E.C., Gimb o R.Y., S a it a M.V. (2017). Long-term organic selenium supplementation overcomes the tradeoff between immune and antioxidant systems in pacu (Piaractus mesopotamicus). Fish Shellfish Immunol., 60: 311-317.

Tort L., B a la s ch J., M a ckenzi e S. (2003). Fish immune system. A crossroads between innate and adaptive responses. Inmunología, 22: 277-286.

Uribe C., Folch H., En ríquez R., Moran G. (2011). Innate and adaptive immunity in teleost fish: a review. Vet. Med-Czech, 56: 486-503.

Yang X., He Y., Chi S., Tan B., Lin S., Dong X., Yang Q., Li u H., Zhang S. (2020). Supplementation with Saccharomyces cerevisiae hydrolysate in a complex plant protein, low-fishmeal diet improves intestinal morphology, immune function and Vibrio harveyi disease resistance in Epinephelus coioides. Aquaculture, 529: 735655.

Ya o Y.-Y., Yang Y.-L., G a o C.-C., Zhang F.-L., Xia R., Li D., Hu J., R an C., Zhang Z., Li u-C l a rke J., Z h o u Z.-G. (2020). Surface display system for probiotics and its application in aquaculture. Rev. Aquacult. 12: 2333-2350.

Y il maz S., S ova M., Ergün S. (2018). Antimicrobial activity of trans-cinnamic acid and commonly used antibiotics against important fish pathogens and nonpathogenic isolates. J. Appl. Microbiol., 125: 1714-1727.

Y $11 \mathrm{maz}$ S., Ergun S., Yig it M., Çelik E.Ş. (2020). Effect of combination of dietary Bacillus subtilis and trans-cinnamic acid on innate immune responses and resistance of rainbow trout, Oncorhynchus mykiss to Yersinia ruckeri. Aquacult. Res., 51: 441-454.

Received: 31 VIII 2020

Accepted: 11 II 2021 